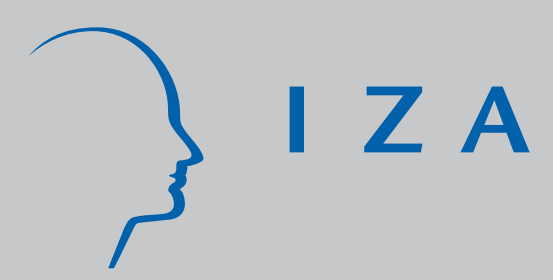

IZA DP No. 5866

Retirement Choice Simulation in Household Settings with Heterogeneous Pension Plans

Jinjing Li

Cathal O’Donoghue

July 2011

Forschungsinstitut zur Zukunft der Arbeit Institute for the Study of Labor 


\title{
Retirement Choice Simulation in Household Settings with Heterogeneous Pension Plans
}

\author{
Jinjing Li \\ Maastricht University \\ Cathal O'Donoghue \\ Rural Economy and Development Programme, Teagasc \\ and IZA
}

\author{
Discussion Paper No. 5866 \\ July 2011
}

IZA

P.O. Box 7240

53072 Bonn

Germany

Phone: $+49-228-3894-0$

Fax: +49-228-3894-180

E-mail: iza@iza.org

\begin{abstract}
Any opinions expressed here are those of the author(s) and not those of IZA. Research published in this series may include views on policy, but the institute itself takes no institutional policy positions.

The Institute for the Study of Labor (IZA) in Bonn is a local and virtual international research center and a place of communication between science, politics and business. IZA is an independent nonprofit organization supported by Deutsche Post Foundation. The center is associated with the University of Bonn and offers a stimulating research environment through its international network, workshops and conferences, data service, project support, research visits and doctoral program. IZA engages in (i) original and internationally competitive research in all fields of labor economics, (ii) development of policy concepts, and (iii) dissemination of research results and concepts to the interested public.
\end{abstract}

IZA Discussion Papers often represent preliminary work and are circulated to encourage discussion. Citation of such a paper should account for its provisional character. A revised version may be available directly from the author. 


\section{ABSTRACT \\ Retirement Choice Simulation in Household Settings with Heterogeneous Pension Plans ${ }^{*}$}

This paper estimates a structured life cycle model of family retirement decision using a unique historical dataset back simulated from Living in Ireland survey. Our model takes the advantages of the dataset and models retirement decisions in terms of monetary and leisure incentives, which reflect the complex welfare system in Ireland. The household extension version of the model adapts a collective modelling approach, where the intra-household bargaining is considered. We further incorporate complimentary leisure, which allows us to analyse the interactions of spouses' retirement timing. This methodology enables us to capture the dynamics of retirement and tax-benefit policies and can be used to simulate the effect of policy reform on household retirement behaviours. The paper, in addition, applies the model to assess individual budgetary implications and the labour market impact of rising the minimum retirement age. Our simulation shows that increasing the minimum age for state pension entitlement to 70 would only delay the retirement by less than 2 years according to the individual based model. When we consider the intra-household bargaining and the higher preference of leisure found in the dual career households, the effect of postponing retirement further declines. The result suggests barely postponing the minimum retirement age for state pension without redefining the occupation and private pension rules will only have limited impact for household retirement behaviour in Ireland.

JEL Classification: J14, J26

Keywords: retirement, choice modelling, microsimulation

Corresponding author:

Cathal O'Donoghue

Rural Economy Research Centre

Teagasc

Athenry, Co. Galway

Ireland

E-mail: Cathal.ODonoghue@teagasc.ie

\footnotetext{
* The authors are grateful for the helpful discussions with Michele Belloni on the development of retirement choice models.
} 


\section{INTRODUCTION}

With many countries around the world facing rapidly ageing demographics, great attention has been paid to the economics of retirement. Population ageing in most developed countries is expected to produce significant public expenditure problems as the cost of public transfers such as pensions, health care and long-term care increases. It is important to understand, not only the immediate effect of retirement policy reforms in terms of fiscal sustainability, but more importantly, the change of retirement behaviour induced by the reforms needs to be understood.

Retirement behaviour modelling is one of the fields that have been continuously developed over the past two decades and various methods have been employed to model the labour supply behaviour of elderly workers. One of the oldest methods is the reduced form model, where social and economic variables of individuals are used to estimate their time of retirement. This model, although convenient for estimating, cannot be used in policy simulation since no aspects of a policy are incorporated into the model, i.e. it assumes a policy to remains stable. In addition, reduced form models are not very successful in explaining the spikes observed in the retirement age distribution. Another popular model, the option value model which was originally suggested by Stock and Wise (1988, 1990), utilises a structural retirement decision model that is characterised by employing utility functions to optimize the retirement decision over the lifetime of a worker (MacDonald, 2006). Previous literature suggests that this model performs well in predicting the behaviour of individuals as it incorporates financial incentives. Although the model is straightforward, the empirical estimation may sometimes be difficult and only a few authors have succeeded in estimating a fully-fledged option value model (Euwals, 2006). Models such as dynamic programming models (e.g. Burkhauser et al., 2004), further incorporate the dynamics of choices over time. However, these models tend to need highly complex computation without offering a better predictive power when compared with the option value approach (Lumsdaine et al., 1992; Burkhauser et al., 2004).

Option value models are typically individual based, which means that the heterogeneity of the household types is largely ignored. This may lead to issues with regard to individuals who do not live in a single person household. In addition, many countries including Ireland, evaluate tax and welfare benefits based on the total income of the household rather than individual income. Furthermore, a few studies have suggested that there is a correlation between spouses' retirement timing (e.g. Maestas, 2001; Gustman, 2000), as a large proportion of spouses are found to retire within a few years of each other. This was observed in the LII dataset, where more than $60 \%$ of the married couples retired within 5 years of each other. The existing reduced form analyses of couples' retirement suggest that this is partly due to complementarities in spouses' tastes for leisure activities, which are present when one or both partners enjoy retirement (Coile, 2000; Banks et al., 2007).

Joint retirement choices models first appeared in 1990 when Hurd (1990) reviewed the joint retirement decision of husbands and wives and later efforts have improved the modelling (Casanova, 2009). More recent versions of the model have incorporated family factors and have been proven to be useful for dual career households (Gustman, 2000). Different theoretical models have been developed for household based modelling and the oldest approach is the unitary model developed by Mincer (1963) and used by Becker (1965) and others. The unitary model treats a household as a single individual and assumes that the Slutsky matrix must be symmetrical. This assumption implies that the marginal compensated wage changes of the two partners must have the same effect on each other's labour supply (van Klaveren et al., 2008). However, this approach is often criticized in the literature, due to the strict assumptions imposed, and many papers have refuted this assumption when using empirical data (Thomas, 1990; Browning et al., 1994; Blundell et al., 2007). 
Another method used to model household behaviour is called the collective approach. This was initially introduced by Chiappori (1988, 1992, 1997) and later used by Apps and Rees $(1988,1997)$. The collective modelling approach assumes that the household decision processes should result in a Pareto-efficient intra-household allocation. Compared with the unitary approach, the assumption in the collective modelling approach seems to be more difficult to reject when tested on an empirical dataset (Cherchye et al., 2009, 2011). To date, there have only been a few papers published on the collective retirement choice model (Michaud and Vermeulen, 2010); however, due to dataset limitations and the limitations of the model, few have considered the comprehensive welfare benefits and DC pensions to which individuals may be entitled to. Other papers have used non-cooperative (strategic) models to analyse household behaviours (Jia, 2003; Chiappori and Donni, 2006). This type of model typically assumes that the outcome of household bargaining results in a Nash or Stackelberg equilibrium. However, this model is less popular due to its complexity and the difficulties in identification.

There are a number of limitations to the existing implementations of household based retirement choice models for policy analysis. Due to the restriction on the model specification calculation and numeric calculation, many models are estimated via approximations, and certain numeric calculations are not feasible for future simulations. Additionally, the construction of social security wealth are typically approximated by a time-series function and combined with some synthetic old age benefits calculations. The heterogeneity of households and the receipt of other social benefits are largely ignored in almost all studies due to dataset limitations and calculation complexity. Finally, with more countries having engaged in pension reform over the recent decades and the gradual move towards DC pension plans, models need to be refined to adopt mixed pension plans within the same dataset.

This paper uses a lifetime discrete choice framework that is in line with the random utility approach. It adopts the collective modelling approach with a household extension to provide increased pension information and estimates a structured model using a unique historical dataset back simulated from the LII survey (Li and O’Donoghue, 2010). The model takes advantages of the dataset and models the retirement decision in terms of the monetary and leisure incentives, which in turn reflects the complicated Irish welfare system. The household extension version of the model adapts the collective modelling approach allowing intra-household bargaining to be considered. This methodology allows the capture of the dynamics of pension and tax-benefit policies, and can be used to simulate the effect of policy reform on household retirement behaviours.

Section 2 covers the background of the Irish pension system and theoretical models are described in section 3. Empirical specifications are presented in section 4, section 5 describes the dataset and section 6 reports the estimation results. Section 7 applies the model to the analysis of a synthetic pension reform of raising the minimum state pension entitlement age.

\section{The BACKgROUND OF IRISH PENSION SYSTEM}

As discussed in detail in the previous paper the Irish tax-benefit system is in many respects similar to the UK welfare state. Many welfare benefits in Ireland are flat rate based, and not earnings related (Evans et al., 2000; Callan, 1997) and Ireland uses a set of means tests and eligibility conditions to cover contingencies such as unemployment, old age disability, lone parenthood etc. (O'Donoghue, 
2003). The Irish pension system is frequently presented as a multi-pillar system and Table 1 provides an overview of the components of the relevant welfare benefits provided for the elderly in Ireland ${ }^{1}$.

Table 1 Irish Pension System

\begin{tabular}{l|l}
\hline 1st Pillar & $\begin{array}{l}\text { Old Age Non-Contributory Pension; } \\
\text { Old Age Contributory Pension; } \\
\text { Invalidity Pension; } \\
\text { Widow, Widower, Orphan and other Pensions Benefits }\end{array}$ \\
\hline $2^{\text {nd }}$ Pillar & $\begin{array}{l}\text { Public service pay-as-you-go schemes; } \\
\text { Funded occupational pension schemes set up by employers }\end{array}$ \\
\hline $3^{\text {rd }}$ Pillar & Supplementary private pensions arranged by individuals \\
\hline
\end{tabular}

Ireland has no single fixed retirement age and this varies depending on occupation and job sector. However, the system provides an incentive for all to retire at age 65/66 regardless of which individuals are employed in. This age has been confirmed by the synthetic analysis undertaken by $\mathrm{Li}$ and O'Donoghue (2011) where it has been shown that the replacement rate for all workers jumps when they become entitled to receive the public state pension.

Since receiving certain old age benefits (e.g., old age contributory pension) in Ireland does not necessarily mean that an individual is out of the labour market, a more strict definition of retirement has been used in this study. Here, it is defined as an individual who has stopped working or receiving unemployment benefit after the age of 55 and who does not then re-enter the labour market.

\section{THEORETICAL MODEL}

Although many pension policy analysis models use a reduced form model, this cannot be used for policy simulation for obvious reasons. First, this model assumes everything to be stable and second, a model is needed that can replicate real life scenarios, which means including all public pensions and private pensions, regardless of whether they are in the form of defined benefit (DB) or DC. Reduced form analysis tends to struggle to explain spikes observed in the retirement age distribution, and can only explain the age-65 spike with limited success. This section presents a fully structured model for analysing the retirement choices within a household.

\section{The Incentive of Retirement}

In order to model the retirement decisions within a household, the retirement incentives must be first understood. Economically speaking, one of the largest incentives of retirement comes from the financial perspective. Pension income is an important source of retirement for most of the elderly population. In Ireland, 59.5\% of individuals receive a public or private pension after retirement, and pensions account for $71.6 \%$ of the total pre-tax income among those aged 65 or above. Li and O'Donoghue (2011) found that there is a link between the replacement rate and the retirement hazard rate when using the LII dataset.

\footnotetext{
${ }^{1}$ This section aims to give a brief description of the current Irish pension system. For a detailed description of the tax benefit system in Ireland and its pension system, please refer to O’Donoghue (2003); Baroni \& O’Donoghue (2009)
} 
Besides the strong financial incentives for retirement, leisure is also a critical component in an individual's retirement choice. As would be assumed, leisure contributes positively to an individual's utility function, just the same as monetary incentives. In a household setting, the utility of leisure is more complex as it might also be dependent on the spouse's status, as a couple may prefer to spend time together. Casanova (2009) reported a correlation of the timing of couples' retirement and suggested that this is due to the complementarity of spouses' tastes for leisure, which are present when one or both partners enjoy retirement.

\section{Base Model Function}

In this paper, a structured life-cycle retirement choice model is described. The model utilises a discrete choice framework (as in Van Soest, 1995; Flood et al., 2004; Michaud and Vermeulen, 2010), which allows the incorporation of a complex non-linear tax benefit system. When determining

whether to retire at a particular age $\tau$, the worker seeks to maximise his/her utility among all possible

retirement ages. Initially the model is individually based and it is assumed that an individual's lifetime utility is constructed of two additive components, the utility from lifetime consumption $(\Sigma C)$ and the utility from lifetime leisure ( $\Sigma L)$, as described in equation (1).

$$
U^{\tau}=v\left(\sum_{s=1}^{T} \delta^{s} C_{s}^{\tau}\right)+u\left(\sum_{s=1}^{T} L_{s}^{\tau}\right)
$$

Where $v(\cdot)$ denotes the utility from consumption and the $v(\cdot)$ the utility from leisure. $\delta^{s}$ is the discount factor which is equal to $\left(\frac{1}{1+\gamma}\right)^{s}$, where $\gamma$ is the interest rate.

In this model it is assumed that either retirement or labour market activity can occur at a particular point but not at the same time. Lifetime consumption is assumed to the same as lifetime earnings, while lifetime leisure is captured by the number of years that are free of labour market activities. For each time period there may be multiple income sources, including wages, non-labour income, benefit from the state if eligible and tax deducted accordingly. Forced retirement is not considered within this model, as retirement is being viewed from the supply side only. Since the labour earnings, pensions and benefits would change with retirement time $R$, the total expected income at time $t$ can be presented as:

$$
Y_{t}^{\tau}=\left(y_{t}^{\text {wage }}+y_{t}^{\text {pension }}+y_{t}^{\text {others }}+y_{t}^{\text {benefits }}-\operatorname{tax}_{t}\right) \mid \tau
$$

The pension component of earnings is constituted of three sub-components; public pension, occupational pension, and private pension. From a life-cycle perspective, the total budget constraint for an individual can be expressed as:

$$
\sum_{i=1}^{t-1}\left(C_{t}^{\tau}\right) \delta^{t}=\sum_{i=1}^{t-1}\left(Y_{t}^{\tau}\right) \delta^{t}
$$

The model assumes perfect capital markets (see Gustafsson, 2001; Apps and Rees 2010) where the budget constraint balances over the lifetime and resources can be saved or borrowed from the future. 


\section{Retirement Model with Household Extension}

As discussed earlier, the individual based model is unable to accurately model the monetary incentives for married couples due to the nature of tax benefit systems. In addition, all household interactions are also ignored. In order to address these two shortcomings, the model was extended to a household setting, which allows spouses to influence each other's decision.

Similar to the individual based model, it was assumed that an individual is rational and chooses to retire at a point which maximizes his/her lifetime utility. The observed pattern of retirements in a household is the result of two maximized utilities. To model this, the collective approach was used due to the simplicity of the modelling whilst also taking into account household bargaining. The model describes a household ${ }_{i}$ 's behaviour as an outcome of maximizing a household's utility function:

$$
U_{i}^{\tau_{m}, \tau_{f}}=\pi_{i} U_{i, m}^{\tau_{m}}+\left(1-\pi_{i}\right) U_{i, f}^{\tau_{f}}
$$

The individual preferences are represented by $U_{i, m}^{\tau_{m}}$ for male and $U_{i, f}^{\tau_{f}}$ for female and the utility weight is presented by a Pareto parameter $\pi$ which is between 0 and 1 . Browning et al. (2006) argued that the model is equivalent to the standard unitary model unless the Pareto parameter is dependent on prices. Following the weight modelling approaches used by van Klaveren (2008) and Michaud and Vermeulen (2010) etc., it was assumed that $\pi_{1}$ varies across households as a function of potential wages. Empirically, the logarithm of the ratio of the male earnings and the female earnings was used as the key variable to model the Pareto weights. Personal characteristics (e.g. education) are assumed to be fully reflected in the potential earning profile. As the parameter always needs to fall between zero and one, the weight model was specified as follows:

$$
\pi_{i}=N\left(\mu \ln \left(\frac{y_{i}^{m}}{y_{i}^{f}}\right)\right)
$$

Where $N(\cdot)$ stands for the standard normal distribution function. As a result, $\pi_{i}$ is always bounded within 0 and 1. $y_{i}$ is the potential earning of a household member if he/she works full time for one year in the labour market. An increase in $\pi_{1}$ implies that the male's utility is weighted more heavily than the female's within that household. The bargaining power is assumed to be even when the potential wage rate is same $\left(y_{i}^{m}=y_{i}^{f}\right)$. By design the weight is symmetrical.

Since only the public consumption information is available for the LII dataset, the weights used in the dataset could not be identified directly, as discussed by Chiappori and Ekeland (2009). Over recent years, there have been several approaches developed for this estimation, including using leisure as exclusive goods (Van Klaveren et al., 2008) or assuming that widows have the same preference as individuals within the household setting (Michaud and Vermeulen, 2009). However, neither method is appropriate in this particular study because here it is the complementary leisure effect that is being specifically modelled, which makes leisure a public goods by design. Additionally, there are only a very limited number of widows entering retirement in the LII dataset and their identification would therefore be difficult or unreliable. As a result, the $\mu_{\mu}$ parameter was fixed according to the values obtained in the previous literature (Browning, 2006; Michaud and Vermeulen, 2009). Given the wide 
range of $\mu$ estimates found, 5 scenarios were considered in order to cover a large range of potential values, and $\mu$ was set at $0.1,0.2,0.3,0.4$ and $0.5^{2}$.

In order to adapt the utility function to a household setting and incorporate some interactions within a household, the base individual utility function (1) was extended. In the household model, it was assumed that all consumptions within the household were public and the preferences of each member allowed for the externalities of the spouse's utility. In addition, following the findings of the literature (Coile, 2000) on the correlation of retirement timing between spouses, a complementary utility of leisure was allowed if the spouse was also retired. Therefore, the leisure function for male household member becomes:

$$
U_{i}^{\tau}=v\left(\sum_{s=1}^{T} \delta^{s} C_{s}^{\tau}\right)+u\left(\sum_{s=1}^{T} L_{s}^{\tau}\right)+p\left(\sum_{s=1}^{T} L_{s}^{\tau}\right) \mid t_{i}^{\tau}<t_{\text {spouse }}^{\tau}
$$

Where $t_{i}^{\tau}$ represents the timing of an individual, $i$ 's retirement. $p(\cdot)$ is the complimentary utility which is only present when the spouse retires at the same time. Individuals without spouses, naturally have a zero complimentary utility, as presented in the individual based model. Accordingly, the budget constraint of the model is also extended to include the sum of two individuals' income and benefits that the household is eligible for.

\section{EMPIRICAL SPECIFICATION}

In order to estimate the models above, it is necessary to transform them into models that can be estimated numerically, and a logarithmic function was used to specify the consumption function $v(\cdot)$ and also the leisure functions $u(\cdot), p(\cdot)$. Given the complexity of modelling leisure, an age-leisure interaction was added to capture the shift in leisure taste over time. Additionally, health status $(H)$ was also incorporated to refine the estimation of leisure. The health variable is defined as the number of expected years that an individual may stay healthy without suffering a major chronic illness from the age of 55 onwards. Complementary leisure is reflected via a dummy variable $d_{i, s}$, which is equal to zero if the spouse is not retired or the individual does not have a spouse. As a result, the statistical form for an individual utility function can be presented as:

$$
\begin{aligned}
U_{i}^{\tau} & =\alpha_{0}+\alpha_{1} \ln \left(\sum_{s=1}^{T} \delta^{s} C_{s}^{\tau}\right)+\alpha_{2} \ln \left(\sum_{s=1}^{T} L_{s}^{\tau}\right) \\
& +\alpha_{3} \cdot \text { age } \ln \left(\sum_{s=1}^{T} L_{s}^{\tau}\right)+\alpha_{4} \ln \left(\sum_{s=1}^{T} L_{s}^{\tau}\right) \cdot d_{i, s}+\alpha_{5} H_{i}
\end{aligned}
$$

Consequently, the collective household utility function becomes:

\footnotetext{
${ }^{2}$ Although these five alternatives may seem to have very different Pareto weight parameters, this was found to have no significant impact on the final estimation results.
} 


$$
\begin{aligned}
U_{h}^{\tau_{m}, \tau_{f}}= & \pi_{h}\left(U_{m}^{\tau}\right)+\left(1-\pi_{h}\right)\left(U_{f}^{\tau}\right) \\
= & \beta_{0}+\beta_{1} \ln \left(\sum_{s=1}^{T} \delta^{s} C_{s}^{\tau}\right)+\beta_{2} \cdot \pi_{h} \ln \left(\sum_{s=1}^{T} L_{s}^{\tau_{m}}\right)+\beta_{3} \cdot\left(1-\pi_{h}\right) \ln \left(\sum_{s=1}^{T} L_{s}^{\tau_{f}}\right) \\
& +\beta_{3} \cdot \pi_{h} \ln \left(\sum_{s=1}^{T} L_{s}^{\tau_{m}}\right) \cdot a g e+\beta_{4} \cdot\left(1-\pi_{h}\right) \ln \left(\sum_{s=1}^{T} L_{s}^{\tau_{f}}\right) \cdot a g e \\
& +\beta_{5} \cdot \pi_{h} \ln \left(\sum_{s=1}^{T} L_{s}^{\tau}\right) \cdot d_{m, s}+\beta_{6} \cdot\left(1-\pi_{h}\right) \ln \left(\sum_{s=1}^{T} L_{s}^{\tau}\right) \cdot d_{f, s} \\
& +\beta_{7} \cdot \pi_{h} H_{m}+\beta_{8} \cdot\left(1-\pi_{h}\right) H_{f}
\end{aligned}
$$

Given the discrete choice setting, there are 21 possible choices of retirement, i.e. between the ages of 55 to 75 , for the individual based model and $441\left(21^{2}\right)$ possible choices of retirement for a married couple. Pareto parameters were estimated independently using the assumptions listed earlier.

As mentioned earlier, accumulated earnings were used as a proxy for lifetime consumption. Since the pre-55 earnings do not vary across different choices, only the sum of expected earnings from age 55 onwards were used as the consumption variable in practise. The wage of the individual positively depends upon the human capital accumulation from their job experience $(h)$, school $(s)$ and market rental rate of human capital $\omega$ at time $t$. As the rate of return to experience falls with experience, the square of experiences was incorporated with a negative coefficient to produce a typical age-earning profile. The model incorporates the assumption that human capital depreciates during periods out of the labour force. Therefore:

$$
\begin{aligned}
y_{t}^{\text {wage }}= & \omega_{t} k_{t} \\
= & \omega_{t} \exp \left(f_{o}+f_{1} \sum_{i=1}^{t-1} s_{i}+f_{2} \sum_{i=1}^{t-1} h_{i}+f_{3}\left(\sum_{i=1}^{t-1} h_{i}\right)^{2}+f_{4} X_{t}\right) \\
& \mu_{1}, \mu_{2}>0
\end{aligned}
$$

Since there is no partial retirement scheme in Ireland, it was assumed that the fluctuations in terms of working hours were minimal for elderly workers and thus the labour supply effects could be ignored. The differences for working hours per individual can be captured by the individual persistent component of the salary. In addition, economic instability was incorporated into the model through the inclusion of the expected unemployment rate at each time $t$. Hence, the expected wage earnings were $y^{\text {wage }}\left(1-u_{t}\right)$. Therefore, the household budget constraint can be expressed as:

$$
\sum_{i=1}^{t-1}\left(C_{t}^{\tau_{m, f}}\right) \delta^{t}=\sum_{i=1}^{t-1}\left(\left(\begin{array}{c}
y_{m, t}^{\text {wage }}\left(1-u_{m, t}\right)+y_{f, t}^{\text {wage }}\left(1-u_{f, t}\right) \\
+y_{m, f}^{\text {pension }}+y_{m, f}^{\text {other }}+y_{t}^{\text {benefits }}-\text { tax }
\end{array}\right) \mid \tau_{m, f}\right) \delta^{t}
$$

Assuming vector $\tau_{i, j}$ represents the choice set that a male retires at time $i$, and a female retires at time $j$, the revealed preference $\tau_{i^{*}, j^{*}}^{*}$ achieves the highest level of utility for both household members, when the household utility reaches its peak. Assuming the disturbances are i.i.d. with a Gumbell (type 1 extreme value) distribution, the model could be estimated using a discrete choice framework with a conditional logit as expressed in equation (11). 


$$
\operatorname{Prob}\left(\text { choice }=\tau_{i j}\right)=\frac{\exp \left(U\left(\tau_{i, j}\right)\right)}{\sum_{i=55}^{75} \sum_{j=55}^{75} \exp \left(U\left(\tau_{i, j}\right)\right)}
$$

Based on the model presented, the key determinants of retirement postponement and the basic assumptions underpinning the motivations influencing an individual's retirement decision can be listed. If $\Delta Y^{\tau(i+1, j)}$ is used to denote the difference in total income due to the shift of retirement timing from $i$ to $i+1$, and $d w_{i}$ the working status of an individual at time ${ }_{i}$, if there is no change in the spouse's retirement timing, then the cost of retirement at time $i$ as opposed to one year later for a male can be expressed as:

$$
\begin{aligned}
U^{\tau_{i+1, j}}-U^{\tau_{i, j}}= & \underbrace{\beta_{1} \cdot \pi_{h} \ln \left(\frac{\Sigma Y^{\tau_{i, j}}+\Delta Y^{\tau_{i+1, j}}}{\Sigma Y^{\tau_{i, j}}}\right)}_{A} \\
& +\underbrace{\pi_{h}\left(\beta_{2} \ln \left(\frac{\Sigma L^{\tau_{i, j}}+1}{\Sigma L^{\tau_{i, j}}}\right)+\beta_{3} \ln \left(\frac{\Sigma L^{\tau_{i, j}}+1}{\Sigma L^{\tau_{i, j}}}\right) \operatorname{age}(i)\right)}_{B} \\
& +\underbrace{\beta_{5} \cdot \pi_{h}\left(\ln \left(\sum_{s=1}^{T} L_{s}^{\tau}\right) \cdot d_{m, s} \mid j=i+1\right)}_{\mathrm{C}}+\underbrace{\beta_{8} \cdot \pi_{h}\left(\Delta H_{m}^{i+1}\right)}_{D}
\end{aligned}
$$

Where

- The utility cost from household earnings changes. This includes the change of labour income, pension entitlement, and household benefits

- The utility cost from leisure due to the change in leisure stream and age

- The potential change in complimentary leisure due to the change of retirement age

- Change in the health variable, depending on the health situation of the individual at time $i$

In addition, the cost of retirement includes the change in human capital, which is modelled through wage equations. Since re-entering the labour market around the moment of retirement in not considered in this model, the change in human capital is only reflected in the gradual increase of earnings if an individual remains in work.

As seen from the decomposition, there are several factors affecting the retirement decision. The greater the cost of retirement in the future, the earlier retirement would occur. Pension plan changes and labour earnings changes affect an individual's retirement decision through item A, while the leisure term B is mostly unaffected except by life expectancy. Individuals with lower earnings tend to have lower costs through A; however, the cost may increase faster than average due to the incremental growth of the limited human capital. As a result, this group may tend to retire earlier, which is consistent with the empirical findings presented by Li and O’Donoghue (2011).

The age-gap present in a household also influences the household's retirement decision through item $\mathrm{C}$, as spouses may retire earlier or later. In the case where a spouse retires early than $i$, then there is no loss in the complimentary utility. However, this will affect the cost of retirement if two spouses' choose to retire close together, as observed in real life. The retirement decision could also be affected by a change of health (item $\mathrm{D}$ ). This suggests that those who are affected most by health are those 
with deteriorating health rather than those with persistent lifetime illnesses as it is only the change that matters. When using the dataset from LII, no consistent pattern for health could be determined across groups with different retirement ages ( $\mathrm{Li}$ and O’Donoghue, 2011). Last but not the least, the Pareto weight $\pi_{h}$ decides the intra-household allocation of consumption, which also affects an individual's retirement decision. While equation (12) only presents the cost of retirement for males, the cost for females follows the same structure since the model is symmetrical. For a single person household (individual model), item $\mathrm{C}$ is always equals to zero, while $\pi_{h}$ remains constant.

From the decomposition of retirement cost, the signs of the coefficients can in theory be predicted. It would normally be expected that utility from consumption is positive, together with the utility from leisure. In addition, since leisure would normally increase in value when getting older, a positive coefficient for the age-leisure interaction would also be expected.

\section{DATASET}

To estimate the model described above, it is necessary to use a dataset which records the social economic variables, earnings and pension profile between age 55-75. This type of dataset, however, is not readily available in Ireland as the comprehensive household survey datasets only covers a limited number of waves. Therefore, this paper uses a simulated long panel dataset derived from the LII longitudinal survey was used. The data covers a wide range of aspects regarding the life of an individual, but does not cover the complete career trajectory needed for pension and retirement modelling. In order to meet the requirements of the model, the historical labour market profile for individuals in the LII dataset were back simulated via a dynamic microsimulation in a reversed direction ( $\mathrm{Li}$ and O'Donoghue, 2010). The simulated dataset matches the reported pension eligibilities, including state pension, occupational pension and private pension, with higher than $95 \%$ accuracy as presented in Table 2.

Table 2 Percentage of Correctly Simulated Eligibility

\begin{tabular}{lcc}
\hline Pension Type & Correctly Simulated & Number of Observations* \\
\hline Contributory State Pension & $96.08 \%$ & 9343 \\
Occupational Pension & $98.25 \%$ & 10030 \\
Private Pension & $97.36 \%$ & 1706 (Year 2000 onwards) \\
\hline Only age 66+ are included for state pension and 65+ for occupational and private pension
\end{tabular}

With the extensive historical information and consistent benefit eligibilities, the monetary earnings of different retirement choices could be extracted and recreated. Retirement in this paper is defined as exiting the labour market after the age of 55 . The retired population has two subsets, those who are officially "retired" and remain active, and those who become permanently inactive in the labour market after a certain age. An individual is considered to be "inactive" if

- They are aged 55 or above and state "not working" as their main economic activity that year

- Does not receive unemployment benefit, since this indicates that the individual is still actively seeking employment

- Their labour income, which could come from the transition period, is less than 50\% of their life average earning level 
It was assumed that an individual retires between the age 55 and 75 as this is the main group of retirees present in Ireland. Individuals who retired outside of this range were excluded. Married individuals between the ages of 55 to 75 who made a transition to retirement within the dataset were selected for inclusion in the model. In order to ensure the quality of the simulated labour market profile, only individuals who worked at least 3 years in the 10 year period prior to retirement were included in the estimations.

Figure 1 Comparison of Reported Retirement and Observed Retirement

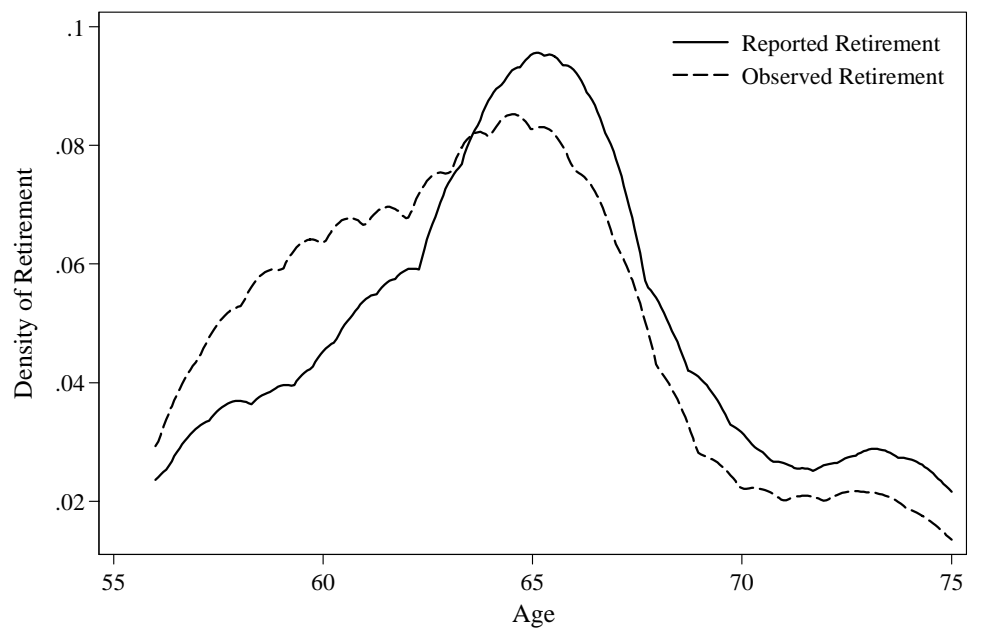

\section{Summary Statistics on Key Variables}

Since each individual is exposed to 21 choices (from age 55 to age 75), the total number of choices ${ }^{3}$ a household can make is $441\left(21^{2}\right)$. A dynamic microsimulation model was used to assist in the calculation of incomes for different retirement scenarios. This calculation retained the household structure of the simulated household, i.e., everyone in the household was simulated throughout the entire time period unless death occurred. The dynamic microsimulation model includes a complex pool of equations which were estimated for the LII dataset. These cover the labour supply module, earning module, state pension entitlement module, occupational pension module and private pension module. With a rich pool of data simulated from the model, income, leisure, and social economics characteristics could be calculated for all the scenarios.

Table 3 Summary of Variables on Estimated Sample

\begin{tabular}{lc}
\hline Variables & Cases \\
\hline Total Number of Individuals & 390 \\
Male & 298 \\
Female & 92 \\
Percentage with at least some college & $16.1 \%$ \\
education & $10.3 \%$ \\
Chronic Illness at the time of retirement & $79.2 \%$ \\
Married &
\end{tabular}

${ }^{3}$ Not all choices may be present due to life expectancy restrictions. 


\begin{tabular}{lc} 
Was in public sector (if working) & $17.5 \%$ \\
Average retirement age & 63.65 \\
\hline Number of Observations & 8190 \\
\hline
\end{tabular}

\section{ESTIMATION RESULTS}

\section{Individual Model}

Estimations were made for both the individual and household based models. While the individual based model was estimated for all retirees, the household based model was only applicable for a dual career household exhibiting a stable marriage. Males and females were estimated separately as they may be subject to very different employment histories and preferences. In addition, the potential differences in preferences between married and single retirees were also considered.

Table 4 presents the estimation results from the individual based models. As would be expected, the lifetime income term is always positive and significant. Leisure is generally highly significant across the models when age-leisure interaction terms are considered at the same time. This positive interaction suggests that individuals value leisure more as they age. However, the coefficients are not the same across all models and differences are found between males and females, and married and single retirees, in terms of income and leisure coefficients. In general, females are more sensitive to both monetary income and leisure change. The leisure term coefficients for the female models are on a few occasions, higher than the male models. This may indicate that a female's retirement decision is more influenced by leisure than a male's retirement decision. It can also be seen that married retirees in general, are less sensitive to income and more sensitive to leisure than single retirees, a pattern that is repeated for both males and females.

Within these estimations, health is not found to be significant, for which there may be several reasons. Firstly, the wage model utilised here is health dependent, which means that the lifetime income is already endogenous with the health variable. Secondly, the health variable, as introduced in the data section, is defined as the number of healthy years following retirement, a variable which as a result, is correlated with leisure, therefore, making the effect of the health variable less obvious. Thirdly, as discussed earlier in the theoretical section, only those individuals with worsening health situations are most likely to be affected and this may also affect the efficiencies of the estimations.

Table 4 Estimation Results from Individual Models

\begin{tabular}{|c|c|c|c|c|c|c|}
\hline \multirow[t]{2}{*}{ Variables } & \multicolumn{3}{|l|}{ Male } & \multicolumn{3}{|l|}{ Female } \\
\hline & $\begin{array}{c}\text { no } \\
\text { spouse }\end{array}$ & $\begin{array}{c}\text { with } \\
\text { spouse }\end{array}$ & $\begin{array}{c}\text { pooled } \\
\text { result }\end{array}$ & $\begin{array}{c}\text { no } \\
\text { spouse }\end{array}$ & $\begin{array}{l}\text { with } \\
\text { spouse }\end{array}$ & $\begin{array}{c}\text { pooled } \\
\text { result }\end{array}$ \\
\hline \multirow[t]{2}{*}{$\begin{array}{l}\text { Lifetime } \\
\text { Income }\end{array}$} & 28.36 & 25.33 & 25.64 & 94.41 & 39.99 & 44.94 \\
\hline & (5.10) & $(2.02)$ & $(1.84)$ & (23.52) & $(6.87)$ & (6.23) \\
\hline \multirow[t]{2}{*}{ Leisure } & 6.86 & 7.21 & 6.66 & 17.31 & 27.22 & 20.04 \\
\hline & $(2.32)$ & (1.12) & $(0.96)$ & (9.62) & $(6.21)$ & $(4.45)$ \\
\hline \multirow[t]{2}{*}{$\begin{array}{l}\text { Leisure Age } \\
\text { Interaction }\end{array}$} & 0.04 & 0.16 & 0.12 & 0.68 & 0.74 & 0.65 \\
\hline & $(0.06)$ & $(0.03)$ & $(0.03)$ & $(0.29)$ & 0.17 & $(0.13)$ \\
\hline \multirow[t]{2}{*}{ Health } & -0.84 & -0.45 & -0.43 & 5.06 & 1.20 & 3.45 \\
\hline & $(0.87)$ & $(0.49)$ & $(0.43)$ & (5.16) & $(2.47)$ & (2.13) \\
\hline
\end{tabular}




\begin{tabular}{lllllll}
\hline $\begin{array}{l}\text { Number of } \\
\text { Observations }\end{array}$ & 1155 & 5103 & 6258 & 567 & 1365 & 1932 \\
\hline
\end{tabular}

(standard errors in parentheses)

\section{Household Model}

Before the estimation of collective models, the sharing rule must first be specified and in this study the Pareto weight was used. Figure 2 illustrates the impact of different sharing parameters on bargaining power. As indicated, males on average have higher bargaining powers due to their higher earning capacities. If the husband's potential earning capacity is three times higher than his wife's, the Pareto weight ranges from 0.54 when $\mu$ is 0.1 , or 0.71 when $\mu$ is 0.5 . This weighting is symmetrical between husband and wife. As can be seen, the higher the $\mu$ value, the higher the standard deviation found in the distribution of the Pareto weight $\pi$. When $\mu$ is very small, e.g. $<0.1$, the model is closer to a unitary model. Due to the data limitations as discussed earlier, the $\mu$ parameter has been fixed in these estimations. However, the structure of the main model estimation is unaffected, as the Pareto weight is seen as an independent variable within the model. In the estimations, five scenarios are considered where $\mu$ ranges from 0.1 to 0.5 .

Figure 2 Distribution of Sharing Parameters with Different $\mu$ Values

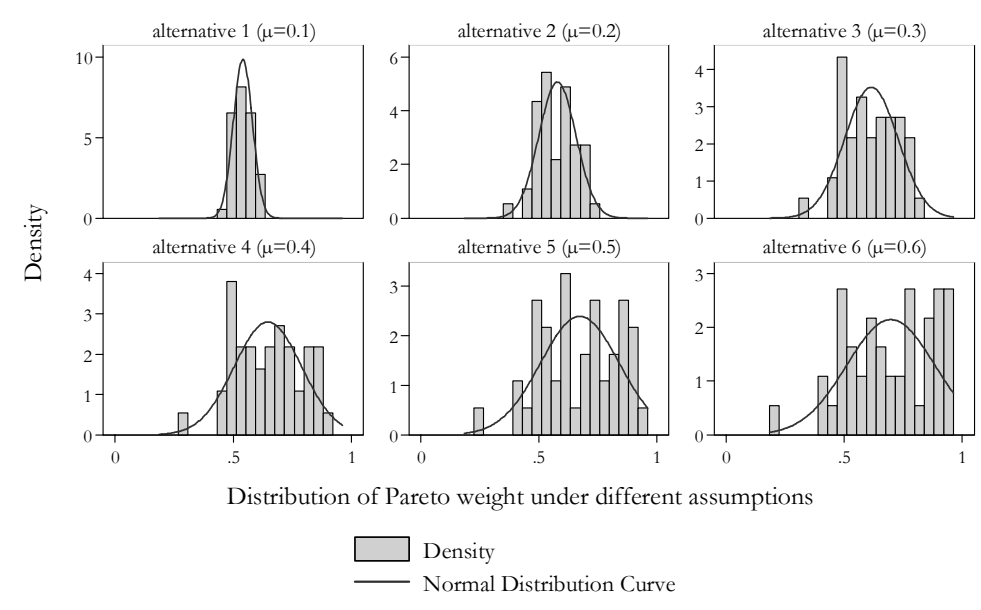

Graphs by alternatives

Table 5 reports the results of the estimations from the collective model. As can be seen, the coefficients are very similar across all scenarios. The standard error of the estimation is much bigger than the differences between scenarios for all coefficients. Similarly to the individual models, income is found to be highly significant, although the numeric value of the coefficients falls considerably. The intercept terms of leisure are not significant except for females. Nonetheless, a highly significant ageleisure interaction across all scenarios was demonstrated for both husbands and wives, which translates to a significant positive leisure effect overall as expected.

In the collective model, complimentary leisure was incorporated as a key variable to interact between males and females utility. The result shows that the effect of a partner's retirement status is highly significant for both males and females, a finding which is consistent with earlier literature reporting that spouses tend to retire very shortly after each other (Gustman and Stienmeir, 2000; Michaud, 2005). Health was shown to be significant at the $10 \%$ level for females but insignificant for males. For 
both the individual model and collective model, females exhibited a higher preference towards leisure compared with males.

Table 5 Estimation Results from Collective Model

\begin{tabular}{|c|c|c|c|c|c|}
\hline Variables & $\begin{array}{c}\text { Scenario } 1 \\
(\mu=0.1)\end{array}$ & $\begin{array}{c}\text { Scenario } 2 \\
(\mu=0.2)\end{array}$ & $\begin{array}{c}\text { Scenario } 3 \\
(\mu=0.3)\end{array}$ & $\begin{array}{c}\text { Scenario } 4 \\
(\mu=0.4)\end{array}$ & $\begin{array}{c}\text { Scenario } 5 \\
(\mu=0.5)\end{array}$ \\
\hline \multicolumn{6}{|l|}{ Shared Variable } \\
\hline $\begin{array}{l}\text { Household Lifetime } \\
\text { Income }\end{array}$ & $\begin{array}{l}14.38 \\
(3.59)\end{array}$ & $\begin{array}{l}14.13 \\
(3.61)\end{array}$ & $\begin{array}{l}13.88 \\
(3.63)\end{array}$ & $\begin{array}{l}13.65 \\
(3.65)\end{array}$ & $\begin{array}{l}13.44 \\
(3.68)\end{array}$ \\
\hline \multicolumn{6}{|l|}{ Husband } \\
\hline Leisure & $\begin{array}{c}5.40 \\
(4.82)\end{array}$ & $\begin{array}{c}5.54 \\
(4.55)\end{array}$ & $\begin{array}{c}5.67 \\
(4.30)\end{array}$ & $\begin{array}{c}5.77 \\
(4.08)\end{array}$ & $\begin{array}{c}5.80 \\
(3.90)\end{array}$ \\
\hline $\begin{array}{l}\text { Leisure } \\
\text { Interaction }\end{array}$ & $\begin{array}{c}0.51 \\
(0.18)\end{array}$ & $\begin{array}{c}0.48 \\
(0.17)\end{array}$ & $\begin{array}{c}0.45 \\
(0.16)\end{array}$ & $\begin{array}{c}0.42 \\
(0.16)\end{array}$ & $\begin{array}{c}0.40 \\
(0.15)\end{array}$ \\
\hline $\begin{array}{l}\text { Complementary } \\
\text { Leisure if spouse } \\
\text { retired }\end{array}$ & $\begin{array}{r}0.70 \\
(0.29)\end{array}$ & $\begin{array}{r}0.74 \\
(0.27)\end{array}$ & $\begin{array}{c}0.76 \\
(0.25)\end{array}$ & $\begin{array}{c}0.76 \\
(0.24)\end{array}$ & $\begin{array}{c}0.77 \\
(0.23)\end{array}$ \\
\hline Health & $\begin{array}{c}0.77 \\
(2.08)\end{array}$ & $\begin{array}{c}0.68 \\
(1.95)\end{array}$ & $\begin{array}{c}0.62 \\
(1.83)\end{array}$ & $\begin{array}{c}0.59 \\
(1.73)\end{array}$ & $\begin{array}{c}0.58 \\
(1.65)\end{array}$ \\
\hline \multicolumn{6}{|l|}{ Wife } \\
\hline Leisure & $\begin{array}{l}18.89 \\
(8.51)\end{array}$ & $\begin{array}{l}18.67 \\
(9.01)\end{array}$ & $\begin{array}{l}18.40 \\
(9.55)\end{array}$ & $\begin{array}{c}18.12 \\
(10.11)\end{array}$ & $\begin{array}{c}17.82 \\
(10.67)\end{array}$ \\
\hline $\begin{array}{l}\text { Leisure } \\
\text { Interaction }\end{array}$ & $\begin{array}{c}0.93 \\
(0.29)\end{array}$ & $\begin{array}{c}1.04 \\
(0.32)\end{array}$ & $\begin{array}{c}1.17 \\
(0.35)\end{array}$ & $\begin{array}{c}1.31 \\
(0.38)\end{array}$ & $\begin{array}{c}1.46 \\
(0.41)\end{array}$ \\
\hline $\begin{array}{l}\text { Complementary } \\
\text { Leisure if spouse } \\
\text { retired }\end{array}$ & $\begin{array}{c}0.71 \\
(0.32)\end{array}$ & $\begin{array}{c}0.77 \\
(0.34)\end{array}$ & $\begin{array}{r}0.81 \\
(0.36)\end{array}$ & $\begin{array}{r}0.82 \\
(0.38)\end{array}$ & $\begin{array}{r}0.82 \\
(0.39)\end{array}$ \\
\hline Health & $\begin{array}{c}6.89 \\
(3.85)\end{array}$ & $\begin{array}{c}7.57 \\
(4.13)\end{array}$ & $\begin{array}{c}8.32 \\
(4.45)\end{array}$ & $\begin{array}{c}9.11 \\
(4.78)\end{array}$ & $\begin{array}{c}9.87 \\
(5.11)\end{array}$ \\
\hline Number of Observations & 19509 & 19509 & 19509 & 19509 & 19509 \\
\hline
\end{tabular}

Compared with individual models, collective model estimates seem to generally have lower coefficients for income and higher coefficients for leisure. This difference in coefficients may reveal differences in the preferences between different social groups. The individual models included all observations, while the household models only used dual career spouses. The difference in coefficients implies a heterogeneity of preferences among the population, and seem to suggest that people with families, especially working spouses, value leisure more than the single population. To eliminate the difference caused by the sampling procedure, the individual models were re-estimated using the same dataset as the collective model. As reported in Table 6, the differences found in the coefficients seemed now to be reduced, thus confirming the speculation that coefficients are heavily influenced by the sample; although the re-estimated coefficients for leisure are generally smaller than the equivalent terms in the collective model.

Table 6 Estimation Results from Individual models using same dataset as collective model

Individual Model $\quad$ Collective Model $(\mu=0.3)$




\begin{tabular}{lcccc} 
Variables & Male & Female & Male & Female \\
\hline Lifetime Income & 8.54 & 14.95 & \multicolumn{2}{c}{13.88} \\
\multirow{2}{*}{ Leisure } & $(2.73)$ & $(3.89)$ & \multicolumn{2}{c}{$(3.63)$} \\
\multirow{2}{*}{ Leisure Age Interaction } & 3.28 & 13.58 & 5.67 & 18.40 \\
& $(2.46)$ & $(4.57)$ & $(4.30)$ & $(9.55)$ \\
Health & 0.30 & 0.45 & 0.45 & 1.17 \\
& $(0.10)$ & $(0.15)$ & $(0.16)$ & $(0.35)$ \\
& 0.32 & 3.43 & 0.62 & 8.32 \\
Number of Observations & $(1.07)$ & $(2.05)$ & $(1.83)$ & $(4.45)$ \\
\hline
\end{tabular}

(standard errors in parentheses)

\section{Predictive Power of the Models}

As one of the main applications of the structured retirement choice model is to evaluate potential reforms, it is important to assess the fitness of the model. Figure 3 plots the difference between predicted retirement age and the actual retirement age. As can be seen, in the individual based model, $76.7 \%$ of the observations have an error of less than 2 years and $94.6 \%$ of the observations fall within an error of 5 years.

Figure 3 Difference Between Predicted and Observed Retirement Age Using the Individual Model

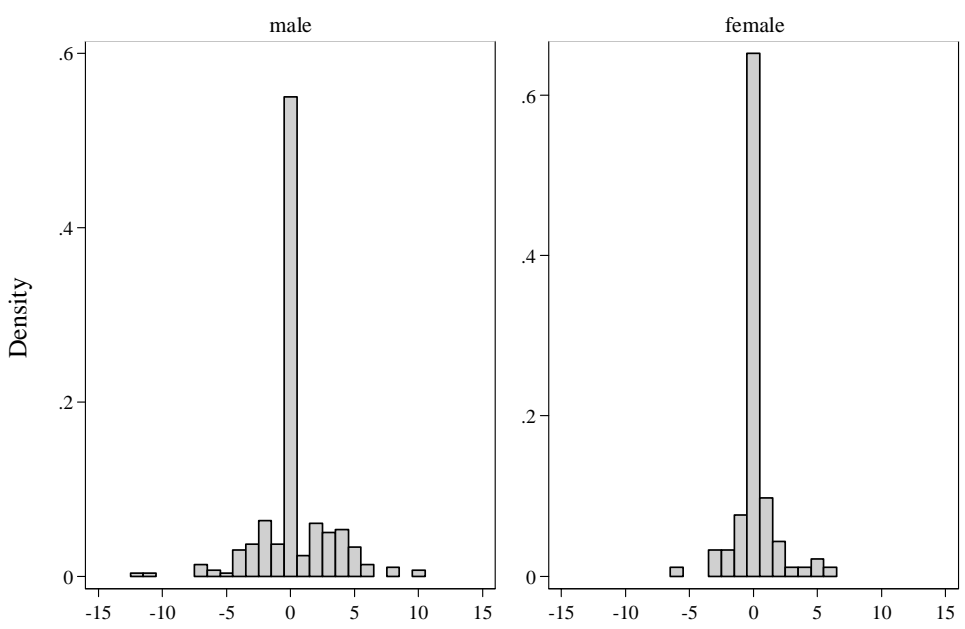

In the collective model, the retirement choice is a vector of two retirement decisions. Consequently in Figure 4, the graph was plotted in a two-dimensional manner, with the x-axis illustrating the error of prediction of the husband's retirement choice, and the y-axis the error of the wife's retirement choice prediction. Since one error pattern may appear several times, the circles were weighted using the frequency of the error patterns. The larger the circle, the greater the number of households that fall into this pattern. Sharing rules did not seem to have any major impact on the predictive power. Figure 5 plots the retirement age distribution under the five scenarios with different $\mu$ values. The resulting curves look very alike and the difference in terms of predicted retirement ages are on average, less than one year. Given that there is no statistical difference between coefficients with different $\mu$ parameters, the median value, $\mu=0.3$, was chosen to validate the predictive power of the model. As 
shown, for $88.9 \%$ of the households the household choice was predicted with neither member of the household displaying an error larger than 5 years. Therefore, the model is able to predict the retirement choice for both a husband and wife with an average error of less than 2 years for $51.1 \%$ of the observations.

Figure 4 Difference Between Predicted and Observed Retirement Choices Using the Household Model

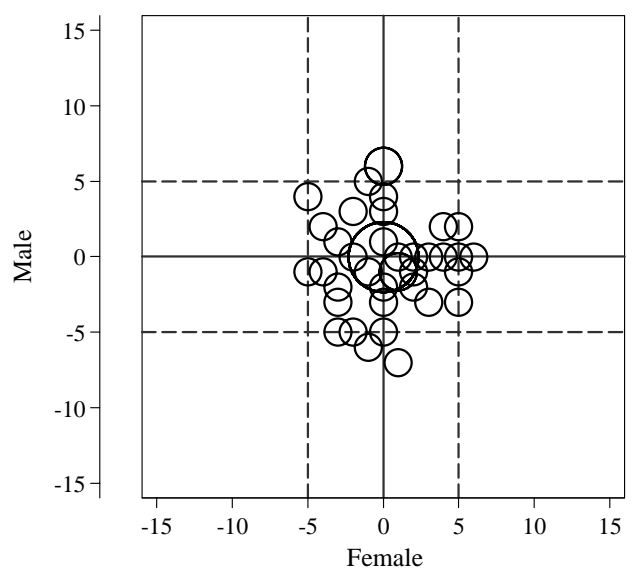

- Difference (bigger circle indicates higher frequency)

Figure 5 The Impact of the $\mu$ Parameter on Collective Model Performance

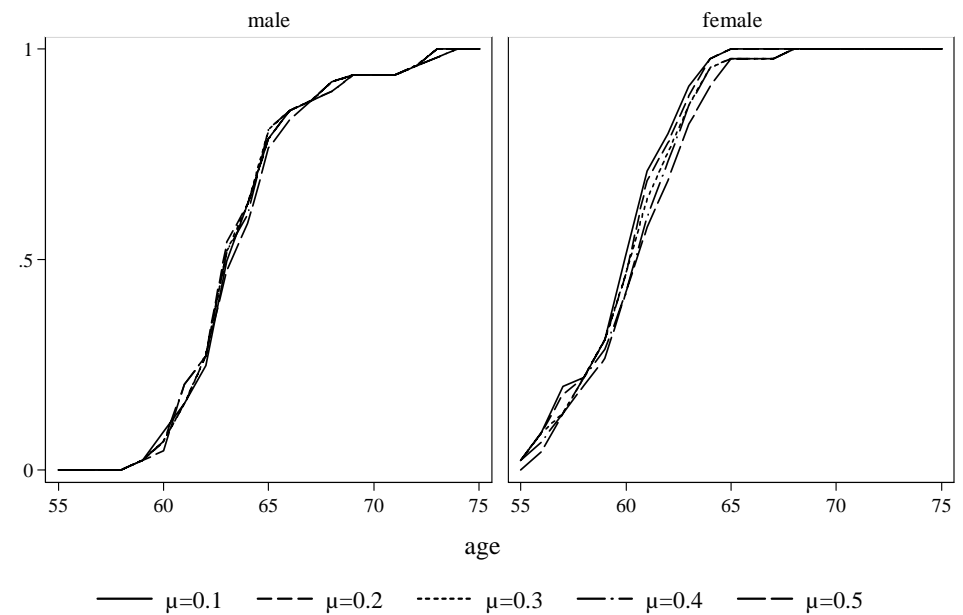

\section{SIMULATION OF A REFORM SCENARIO}

One of the main advantages of a structured retirement model is that it can be used for policy simulation. As European countries are actively seeking to postpone the minimum full retirement age, the model presented in this paper offers opportunities for exploring the potential effect of raising the minimum retirement age. The reform scenario tested here, assumes a postponement of all state pension pay-outs until age 70, instead of the current age of 65/66 for both contributory and noncontributory pensions. All other rules of the tax benefit system remain the same and occupation and 
private pension pay-outs are not affected by the change. This would result in a decreased income level between the ages of 65 and 70 due to the missing state pension. However, depending on the income level the effect might be different due to the progressive nature of the tax system.

The simulation therefore recalculates the potential lifetime earnings and changes in welfare benefit entitlements, but does not change life expectancy, leisure, preferences or any other non-monetary variables. One potential problem of the scenario is the change of the unemployment rate. With the possibility of working until a later age, the employment rate of an elderly worker would increase as more people would have the opportunity of working if they so wished, e.g. public sector workers. As a result, using the existing unemployment rate may underestimate an individual's expected income after the reform. Therefore, in order to control the potential change of the labour market structure, the risk of unemployment within the 5 years after the original individual retirement age is assumed to be the same as the risk immediately before retirement. The bargaining power within a household is assumed not to have been affected by the new pension rule and there are no changes in terms of eligibility. The reform is implemented as if all households in the dataset are subject to the new regulation at the time of retirement and the reform is simulated using both individual and household based models.

\section{Change in the Budget Constraint}

The direct consequence of the reform is a change in lifetime income, which is the result of several sources. First, abandoning the state pension between the ages of 65 to 70 decreases the earnings for those who retire before the age of 66. Second, the change of the unemployment rate increases the income level if individuals choose to continue working after their original retirement age. The reform makes later retirement more attractive as it increases the cost of retiring at the same age. In addition to the direct changes stated above, there is a third source of change. In the case of a household which has more than one family member, the change in the total income would affect the tax-benefit eligibility as well. As a result, there may be an extra household based benefit or heavier tax cost, depending on the household's circumstances.

Table 7 reports the change of the budget constraints in logarithmic term for the datasets. For the dataset that covers both singles and couples, the net change of the reform is negative if retirement occurs at an early age, although this turns positive when retiring at a later age. This is expected as the early retirees have lost their state pension before the age of 70 , while late retirees are benefiting from the lower unemployment rate, which translates into a higher expected income. The trend is similar between mean and median values, although the effect is greater if presented through the mean because of the bias towards high income earners. The change in the budget constraint implies that there is a monetary incentive to retire later, although the effect might be limited given certain income brackets are more likely to be affected than the others.

Table 7 Change of the Budget Constraint for the Simulated Reform

\begin{tabular}{|c|c|c|c|c|c|c|c|c|}
\hline \multirow[b]{3}{*}{$\begin{array}{l}\mathrm{Ag} \\
\mathrm{e}\end{array}$} & \multicolumn{4}{|c|}{ Individual Models (All observations) } & \multicolumn{4}{|c|}{ Collective Models (only couples) } \\
\hline & \multicolumn{2}{|c|}{$\begin{array}{l}\text { Mean value of } \\
\text { change }\end{array}$} & \multicolumn{2}{|c|}{$\begin{array}{l}\text { Median value of } \\
\text { change }\end{array}$} & \multicolumn{2}{|c|}{$\begin{array}{l}\text { Mean value of } \\
\text { change }\end{array}$} & \multicolumn{2}{|c|}{$\begin{array}{l}\text { Median value of } \\
\text { change }\end{array}$} \\
\hline & Male & Female & Male & Female & Male & Female & Male & Female \\
\hline 55 & -0.053 & -0.034 & -0.014 & -0.005 & -0.045 & 0.014 & -0.012 & -0.004 \\
\hline 56 & -0.050 & -0.031 & -0.013 & -0.005 & -0.044 & 0.014 & -0.012 & -0.002 \\
\hline
\end{tabular}




\begin{tabular}{lllllllll}
57 & -0.047 & -0.024 & -0.011 & -0.004 & -0.044 & 0.015 & -0.012 & -0.001 \\
58 & -0.042 & -0.016 & -0.009 & -0.003 & -0.043 & 0.016 & -0.013 & 0.000 \\
59 & -0.036 & -0.007 & -0.004 & -0.002 & -0.042 & 0.018 & -0.012 & 0.000 \\
60 & -0.023 & 0.003 & -0.002 & -0.002 & -0.040 & 0.020 & -0.011 & 0.000 \\
61 & -0.009 & 0.008 & 0.000 & -0.002 & -0.033 & 0.020 & -0.011 & 0.000 \\
62 & 0.006 & 0.016 & 0.000 & -0.001 & -0.026 & 0.019 & -0.009 & 0.000 \\
63 & 0.025 & 0.027 & 0.000 & 0.000 & -0.015 & 0.020 & -0.004 & 0.000 \\
64 & 0.046 & 0.044 & 0.000 & 0.000 & -0.009 & 0.021 & -0.002 & 0.000 \\
65 & 0.070 & 0.061 & 0.013 & 0.004 & 0.003 & 0.021 & 0.000 & 0.001 \\
66 & 0.093 & 0.084 & 0.022 & 0.008 & 0.018 & 0.020 & -0.003 & -0.007 \\
67 & 0.104 & 0.085 & 0.019 & 0.001 & 0.033 & 0.013 & -0.007 & -0.018 \\
68 & 0.111 & 0.081 & 0.017 & -0.009 & 0.042 & 0.002 & -0.007 & -0.028 \\
69 & 0.114 & 0.084 & 0.008 & -0.013 & 0.050 & -0.010 & -0.004 & -0.039 \\
70 & 0.108 & 0.090 & -0.003 & -0.022 & 0.050 & -0.017 & -0.014 & -0.043 \\
71 & 0.117 & 0.109 & 0.007 & -0.010 & 0.054 & -0.012 & -0.015 & -0.043 \\
72 & 0.124 & 0.113 & 0.011 & -0.010 & 0.056 & -0.013 & -0.013 & -0.047 \\
73 & 0.133 & 0.117 & 0.016 & -0.010 & 0.062 & -0.011 & -0.012 & -0.048 \\
74 & 0.141 & 0.121 & 0.024 & 0.002 & 0.065 & -0.009 & -0.010 & -0.046 \\
75 & 0.150 & 0.124 & 0.041 & 0.003 & 0.071 & -0.008 & -0.005 & -0.044 \\
\hline
\end{tabular}

N.B. change is defined as $\ln \left(y^{*} / y\right)$, collective model reports the budget change at household level

For the collective model, the pattern is more complicated due to the consideration of both dimensions, i.e. husband and wife. As a result, Table 7 only reflects the average changes in the household budget due to the reform. The budget change at the different retirement age for males follows a similar pattern as in the individual models, but for females, the reform causes a declining budget constraint at a later age rather than increasing trend. This is due to the fact that within the dataset, very few females retire later and in addition, female earnings have a lower impact on average on the household budget. It is possible that under certain circumstances, the loss of the state pension outweighs the potential gains of postponing retirement. To further illustrate the complex interaction of incomes, tax benefits and retirement ages, a heat map was plotted for the dataset containing couples. As can be seen in Figure 6, the general pattern shows that a household can benefit from the reform if both the husband and wife retire later. When combining the results from Table 7 and Figure 6, it would be expected that the reform on average, would affect males more than females due to a higher change in the budget constraint. Comparing the individual models and the household models, it would be expected that couples would be less affected by the reform due to the smoothing effect of multiple income sources, a prediction which is reflected by the smaller changes observed. 
Figure 6 Change of the Budget Constraint for the Simulated Reform (Household)

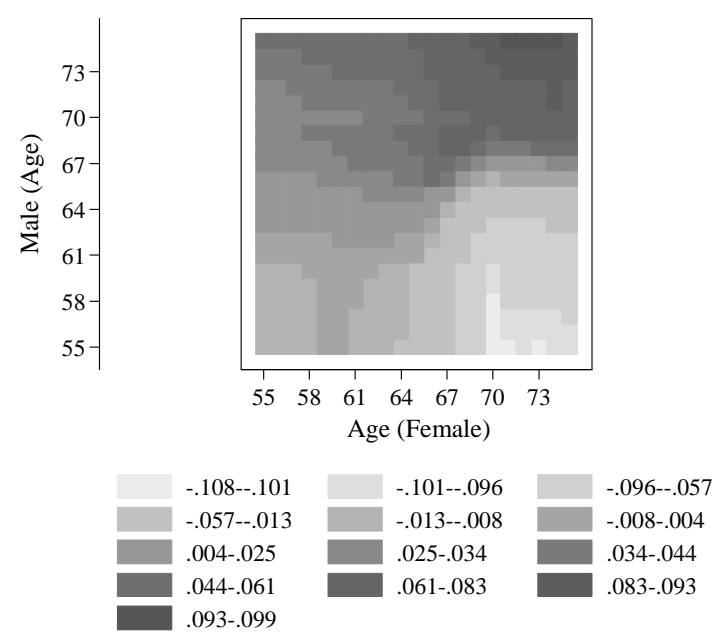

\section{Result from the Individual Based Model}

Simulating pension reform using individual based models requires some extra assumptions. As the original model is estimated on the condition that the spouse retirement timing is fixed, this implies that all choices are independent within the simulation, no matter how a household is structured. To illustrate the effect of the reform, a hazard graph of retirement for males and females was plotted separately (Figure 7). The solid line represents the percentage of people who retired at a certain age, while the dashed line shows the equivalent percentage following a rise in the minimum retirement age. As can be seen, the increase of the minimum state pension entitlement age would change the retirement pattern for both males and females and on average, the retirement age is postponed by 1.91 years for males and 1.80 years for females.

Figure 7 The effect of retirement reform (individual based model)

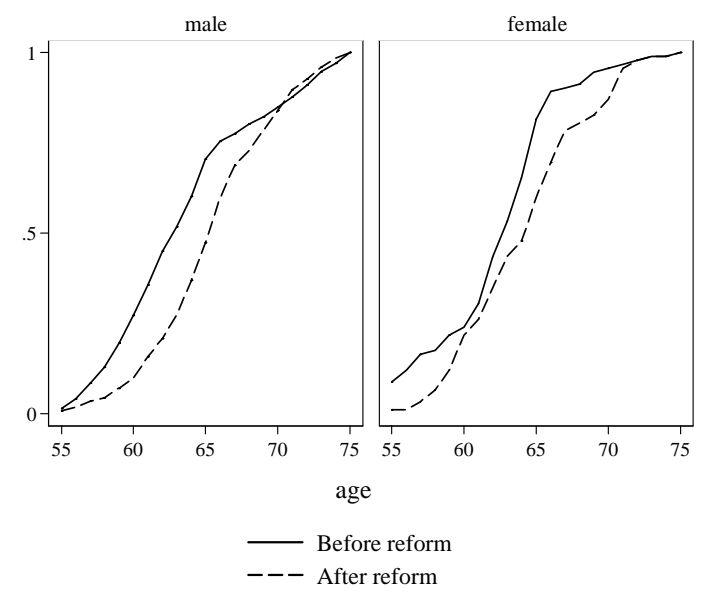

Graphs by sex 


\section{Result from the Collective Model}

Since the sharing rules do not affect the predictive power of the model significantly, the median value of 0.3 was continued to be used as the sharing rule parameter. In the household setting, where consumption is public and complimentary leisure is dependent on the retirement status of the spouse, the simulation result differs from that exhibited in the individual model. Compared with the simulation results from the pure individual models estimated earlier, the household model based simulation suggests that on average, males and females postpone their retirement by $0.5 \sim 0.6$ years. As can be seen in Figure 8, the density of retirement for males around 65 is now reduced. However, the hazard rate of retirement does not alter significantly before the age of 60 or after the age of 70 . As far as females are concerned, the number of individuals who retire at a very early age, i.e. around 55 , has declined, but the hazard rate after the age of 60 does not change significantly.

Compared with the simulation results from the earlier individual models, the effect of reform seems to be smaller and this is consistent with what the budget constraint indicates. The change to the household budget constraint is smaller than the change to the individual budget constraint, as presented in Table In addition, individual models and collective models are estimated on two different samples which have very different preferences for money and leisure. In order to isolate the effect of the model differences, the individual based simulation model was also run in order to compare the results. The result from the individual based models using the household model dataset is represented by the long dashed line in Figure 8. This new simulation suggests that the result from the individual model is very close to the result from the collective model, although it seems to have a slightly larger effect, 0.1 0.2 years extra. The differences between the models are mainly due to the calculation of tax-benefits and the interactions within a household. Complimentary leisure could potentially reduce the effectiveness of the reform as delaying retirement may reduce the total welfare of the household, depending on the time of the spouse's retirement.

Figure 8 The Effect of Retirement Reform (collective model)

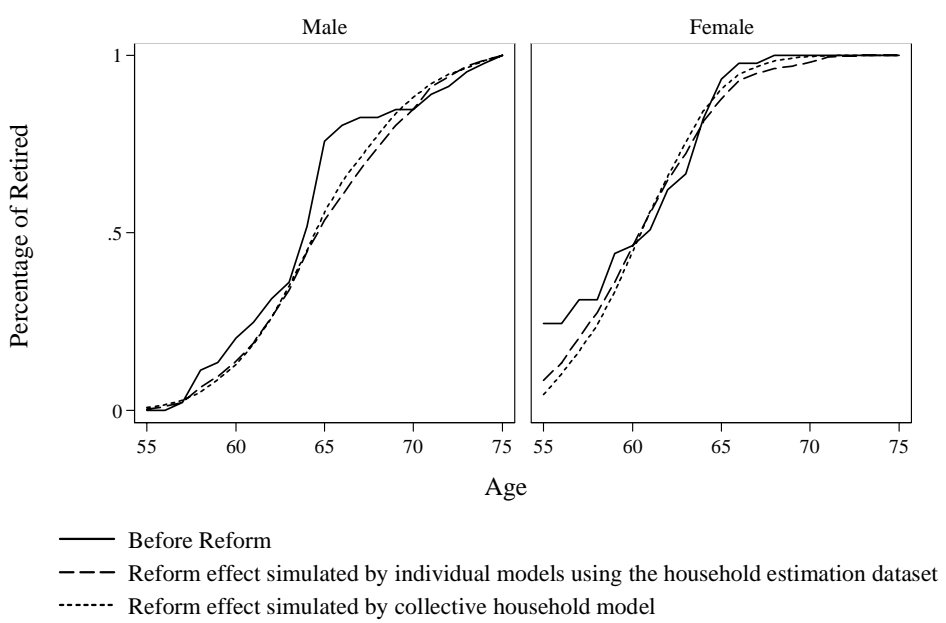

\section{CONCLUSION}

This paper presented a structural retirement choice model to analyse the labour supply behaviour of elderly workers which is line with the random utility approach used by Van Soest (1995). The model 
explicitly incorporated the personal labour trajectory, DB/DC pension entitlements, detailed retirement regulations and the tax benefit system. Two variations of the model were presented, one which is individual based and another which is a collective household model, in which different preferences and bargaining are explicitly allowed in order to reach the observed household allocations. The intra-household allocations were assumed to be Pareto efficient as in the typical collective models suggested by Chiappori $(1988,1992)$. Complimentary leisure was incorporated into the model, thereby allowing further analysis of the interactions of spouses' retirement timing as previously found in the literature (Maestas, 2001; Gustman, 2000).

This paper used a unique historical dataset that has been extensively enriched based on an eight-wave Irish survey dataset using the method described by Li and O'Donoghue (2010). Most parameters from the models were found to be significant and matched our initial expectations. It was found that individuals positively valued leisure and income as expected, and a gradual increase in leisure preference was observed for all individual ages. In the collective household model, complimentary leisure was found to be highly significant, suggesting that the retirement decision is dependent on a spouse's choices. No significant effect of health was found. The health variable was defined as the number of healthy labour free years, which by the definition used in this study is correlated with earnings and leisure. Both individual and collective models were tested to validate their predictive power. The results suggest that the models are able to replicate most retirement choices with an error of less than 2 years.

Additionally, this paper also simulated a potential state pension reform. A scenario was envisaged whereby the minimum age for claiming the Irish state pension was raised from 65 to 70 . This reform, the simulation suggested, delays the average retirement age. However, the collective model result differed from the individual model result. The simulation based on the individual model suggested that elderly workers would postpone their retirement by about 1.8 1.9 years on average, while the collective model suggested that the effect was only around $0.5 \sim 0.6$ years.

The differences between the models were largely due to differences in monetary structure and leisure preferences between dual career household members and the general population. Additionally, the pension reform had a smaller impact on the household budget of dual-career households than for single career households. When using the same dataset, most differences in terms of retirement age distribution were dramatically reduced. Furthermore, the calculation of welfare benefits and family interactions also contributed to the differences observed. The tax-benefit system in Ireland is household-based, and the individual-based model did not take into account the effect of regulation change on other household members. Additionally, the existence of the complimentary leisure term in the collective model also acted as a barrier if an individual decided to postpone retirement beyond the year of their spouse's retirement. This finding suggests that dual-career households have very different leisure preferences compared with single retirees. As a result, a simulation exercise based purely on the individual model may distort the reform effect for dual career households. Combining all of the results presented, a tentative conclusion can be reached that by raising only the minimum retirement age for state pension without changing any other regulations does delay retirement but the effect is probably smaller than may have been expected.

It should also be noted that the models presented in this paper also have their drawbacks. First, the model is estimated based on an expanded household survey dataset which does not contains as many observations as would be present in a national administrative dataset. However, the household survey dataset does provide some important accurate information that an administrative dataset may not provide e.g. information on education. Second, the model assumes that individuals are rational but 
does not allow changes in family formation. These assumptions may not hold in real life where the dynamics of the life expectancy, income, and family formation are typically much more complex. Future research could incorporate more uncertainties and dynamics into the model to account for these limitations. Finally, since the bargaining parameters cannot be fully identified using the available dataset, the model was estimated using a wide range of potential parameters and median values for the simulation exercise. The results show that the model estimates are robust across all scenarios but could be further improved by access to the related variables.

\section{REFERENCES}

Apps, P., Rees, R., 2010. Family labor supply, taxation and saving in an imperfect capital market. Review of Economics of the Household, 1-27.

Apps, P.F., Rees, R., 1988. Taxation and the Household. Journal of Public Economics 35, 355-369.

Apps, P.F., Rees, R., 1997. Collective labor supply and household production. The Journal of Political Economy 105, 178-190.

Banks, J., Blundell, R., Casanova, M., 2007. The dynamics of retirement behavior in couples: Evidence from the UK and the US. Department of Economics, UCLA, mimeo.

Baroni, E., O'Donoghue, C., 2009. Research Working Paper 2009/09: Poverty Impact of State Pension Reform on the Elderly: an analysis of reform proposals in the 2007 Irish Green Paper. Combat Poverty Agency.

Becker, G.S., 1965. A Theory of the Allocation of Time. The economic journal 75, 493-517.

Belloni, M., Alessie, R., 2010. Retirement choices in Italy: what an option value model tells us. Tinbergen Institute Discussion Papers.

Blundell, R., CHIAPPORI, P.A., Magnac, T., Meghir, C., 2007. Collective Labour Supply: Heterogeneity and Non Participation. Review of Economic Studies 74, 417-445.

Browning, M., Bourguignon, F., Chiappori, P.A., Lechene, V., 1994. Income and outcomes: A structural model of intrahousehold allocation. The Journal of Political Economy 102, 1067-1096.

Browning, M., Chiappori, P.A., Lechene, V., 2006. Collective and unitary models: A clarification. Review of Economics of the Household 4, 5-14.

Browning, M., Chiappori, P.A., Lewbel, A., 2006. Estimating consumption economies of scale, adult equivalence scales, and household bargaining power. University of Oxford Discussion Paper.

Burkhauser, R.V., Butler, J.S., Gumus, G., 2004. Dynamic programming model estimates of Social Security Disability Insurance application timing. Journal of Applied Econometrics 19, 671-685.

Callan, T., 1997. Income Support and Work incentives: Ireland and the UK. Economic and Social Research Institute (ESRI).

Casanova, M., 2009. Happy together: A structural model of couples’ joint retirement choices. Mimeo, UCLA.

Cherchye, L., De Rock, B., Vermeulen, F., 2009. Opening the black box of intra-household decisionmaking: theory and non-parametric empirical tests of general collective consumption models. Journal of Political Economy 117, 1074-1104. 
Cherchye, L., De Rock, B., Vermeulen, F., 2011. The Revealed Preference Approach to Collective Consumption Behaviour: Testing and Sharing Rule Recovery. The Review of Economic Studies 78, 176.

Chiappori, P.A., 1988. Rational household labor supply. Econometrica: Journal of the Econometric Society, 63-90.

Chiappori, P.A., 1991. Nash-bargained household decisions: a rejoinder. International Economic Review 32, 761-762.

Chiappori, P.A., 1992. Collective labor supply and welfare. The Journal of Political Economy 100, 437-467.

Chiappori, P.A., 1997. Introducing household production in collective models of labor supply. The Journal of Political Economy 105, 191-209.

Chiappori, P.A., Ekeland, I., 2009. The Microeconomics of Efficient Group Behavior: Identification1. Econometrica 77, 763-799.

Coile, C., Gruber, J., 2000. Social security and retirement. National Bureau of Economic Research Cambridge, Mass., USA.

Esping-Andersen, G., 1990. The three worlds of welfare capitalism.

Euwals, R., Van Vuuren, D., Wolthoff, R., 2006. Early retirement behaviour in the Netherlands: Evidence from a policy reform. IZA.

Evans M., O.D., C. and Vizard, P., 2000. Means Testing and Poverty in 5 European Countries, in: V., A. (Ed.), Le Politiche Sociali in Italia ed in Europa Coerenza e Convergenza nelle Azioni 19971999, Bologna: il Mulino.

Flood, L., Hansen, J., Wahlberg, R., 2004. "Household Labor Supply and Welfare Participation in Sweden," Journal of Human Resources, University of Wisconsin Press, vol. 39(4).

Gustafsson, S., 2001. Optimal age at motherhood. Theoretical and empirical considerations on postponement of maternity in Europe. Journal of Population Economics 14, 225-247.

Gustman, A.L., Steinmeier, T.L., 2000. Retirement in dual-career families: a structural model. Journal of Labor Economics, 503-545.

Hurd, M.D., 1990. The joint retirement decision of husbands and wives. University of Chicago Press, 1990.

Jia, Z., 2003. A mixture model of household retirement choice. University of Oslo.

Li, J., O'Donoghue, C., 2010. Simulating Histories for Dynamic Microsimulation Models, in: O’Donoghue, C. (Ed.), Life-Cycle Microsimulation Modelling: Constructing and Using Dynamic Microsimulation Models. LAP LAMBERT Academic Publishing.

Li, J., O'Donoghue, C., 2011. Incentives of Transition to Retirement for Elderly Workers: Analysis through Actual and Simulated Replacement Rate.

Lumsdaine, R.L., Stock, J.H., Wise, D.A., 1992. Three models of retirement: Computational complexity versus predictive validity. University of Chicago Press.

MacDonald, B.J., Cairns, A.J.G., 2006. Three Retirement Models for Defined Contribution Pension Plan Members: A Simulation Study. Citeseer.

Maestas, N., 2001. Labor, love and leisure: complementarity and the timing of retirement by working couples. Berkeley: Xerox. 
Michaud, P.C., Vermeulen, F., 2010. A collective labor supply model with complementarities in leisure: Identification and estimation by means of panel data. Labour Economics.

Mincer, J., 1963. Market prices, opportunity costs, and income effects. Measurement in economics, 67-82.

O’Donoghue, C., 2003. Redistributive forces of the Irish tax-benefit system.

Stock, J.H., Wise, D.A., 1988. Pensions, the option value of work, and retirement. National Bureau of Economic Research Cambridge, Mass., USA.

Stock, J.H., Wise, D.A., 1990. The pension inducement to retire: An option value analysis. University of Chicago Press, 1990.

Thomas, D., 1990. Intra-household resource allocation: An inferential approach. The Journal of Human Resources 25, 635-664.

Van Klaveren, C., Van Praag, B., Maassen Van Den Brink, H., 2008. A public good version of the collective household model: an empirical approach with an application to British household data. Review of Economics of the Household 6, 169-191.

Vermeulen, F., 2006. A collective model for female labour supply with non-participation and taxation. Journal of Population Economics 19, 99-118. 